\title{
Pleural mesothelioma in a brake mechanic
}

\author{
M HUNCHAREK, ' J MUSCAT, ${ }^{2}$ J V CAPOTORTO, ${ }^{3}$ \\ From the Boston University School of Medicine, ${ }^{1}$ Boston, Massachusetts, USA, and Canadian Tumor Reference \\ Center, National Cancer Institute of Canada, Ottawa, Canada, Division of Cancer Control, ${ }^{2}$ Memorial Sloan- \\ Kettering Cancer Center, New York, USA, and University of Bologna School of Medicine, Bologna, Italy
}

\begin{abstract}
A high risk for the development of diffuse pleural mesothelioma is known to exist in various occupational settings associated with the use of asbestos.' Although a serious hazard has been recognised among asbestos miners, millers, and shipyard workers, recent evidence suggests that a high risk of mesothelioma may exist among occupational groups previously thought to be at low risk for developing this neoplasm. ${ }^{23}$
\end{abstract}

Over the past 40 years, occasional reports of asbestosis among "brake liners" and "brake lining weavers" have been reported. ${ }^{45}$ Lung cancer and mesothelioma among these workers initially seemed to be limited to those working in friction product manufacture, although more recent data indicate that a significant risk of mesothelioma may exist among workers engaged in installing and repairing friction materials. ${ }^{6}$

We review a case of pleural mesothelioma in a car brake mechanic whose only known exposure to asbestos (chrysotile) was from clutch and brake repair work over 11 years. Since asbestos related mesothelioma in brake mechanics has received little attention and since the carcinogenic potential of chrysotile asbestos in man is currently controversial, a short report on this topic appears justified.

\section{Case report}

A 47 year old, lifetime non-smoking man was admitted to another hospital in November 1983 with a one week history of right pleuritic chest pain, shortness of breath, and dyspnoea on exertion. He had lost $10 \mathrm{lbs}$ $(4.5 \mathrm{~kg})$ in the three months before admission. Previous medical history was negative except for exposure to "carborator cleaner" in 1973 which required admission to hospital. He also had a history of recurrent pleural effusion since 1978. (A thorough check up for a right pleural effusion in 1978 was negative for malignancy and of uncertain aetiology).

Chest $x$ ray examination at the time of admission

Accepted 18 January 1988 showed a large opaque density at the right lung base with erosion along the inferior margin of the 8 th and 9th right posterior ribs. A CT scan showed total encasement of the right hemithorax with a nodular pleural mass that extended into the chest wall with rib destruction in the posterior base of the hemithorax. Massive mediastinal nodal involvement was also noted. Excisional biopsy at this time showed malignant mesothelioma of the epithelial subtype. The left lung field and pleura were free of disease.

Chemotherapy consisting of cis-platinum, adriamycin, and cyclophosphamide (Cytoxan) was started in November 1983. Although six monthly cycles of chemotherapy were initially planned, the patient refused further treatment in March 1984 and was subsequently lost to follow up until 1986.

He was readmitted to hospital in May 1986 with increasing dyspnoea and was treated supportively. He had a gradual downhill course and died in late May 1986. Necropsy showed malignant mesothelioma of the right pleura with invasion of the right lung, right chest wall, mediastinum and mediastinal lymph nodes, pericardium, and diaphragm. Metastases were found in the left lung and heart.

Histochemical staining of tumour tissue obtained at necropsy provided additional support for the diagnosis of malignant mesothelioma; PAS stain for mucin was negative and alcian blue positive materials were observed in cellular vacuoles and the stroma. Immunocytochemically, the cells were characterised by the absence of carcinoembryonic antigen and the presence of cytokeratin. On electron microscopic examination of the tumour, well developed nucleoli and microvilli were noted and the findings were considered "consistent with mesothelioma."

This patient had been employed in various occupations spanning about 30 years. From age 18 to 21 he was an aircraft mechanic in the United States Army. After discharge from the Army he was employed for three years (until age 23) in a heavy equipment factory. From age 24 to 29 (1961) he worked on the assembly line of two major United States car manufacturing plants. He was not known to have been exposed to asbestos in any of these 
occupations, nor could he recall any non-occupational or environmental exposure to asbestos during this period.

Interestingly, from age 30 to 41 (1966-75) the patient worked as a brake mechanic in five different service stations/car dealerships. During this employment he did primarily brake and clutch repair, engine overhauls, and automatic transmission and electrical system repair. He reported exposure to asbestos from clutches, the fly wheels, and brakes and that he often used compressed air to "blow out brake drums" which created "dusty working conditions." He reported occasionally using a "face mask," the exact type of which was unknown.

From age 41 until the time of diagnosis, at age 47, he worked in a "wrecking yard." No exposure to asbestos was known to have occurred at this job site. He was totally disabled from the time of diagnosis to death and was unable to work during this interval.

\section{Discussion}

Mesothelioma is now recognised as a major cause of death among occupational groups exposed to asbestos. Since the establishment of a clear association between the inhalation of asbestos and mesothelioma in the late 1960s, several occupational groups have been identified as being "at risk" including miners, millers, and factory workers. More recently, occupational groups using various asbestos products such as insulators, pipe fitters, and railway workers, have been shown to experience a relatively high incidence of this tumour.? In addition, household contacts of asbestos industry workers have been described as being "at risk," demonstrating that "secondary" or "bystander" exposure to asbestos may represent a serious health hazard. ${ }^{8}$

It has been suggested that exposure to asbestos occurs during car brake lining repair and installation ${ }^{9}$ and several studies have documented measurable concentrations of asbestos fibres in the work environment of individuals engaged in such operations. ${ }^{10}$ Rohl et al in 1976 conducted a study to evaluate the exposure to asbestos of workers engaged in brake lining maintenance and brake shoe installation. ${ }^{10}$ Residual dust from brake linings was analysed by $x$ ray diffraction, transmission electron microscopy, selected area electron diffraction, and electron microprobe analysis. Chrysotile asbestos was found in all dust samples taken from car brake drums, accounting for between $2 \%$ and $15 \%$ of each sample. Both fibre and fibril forms were found.

Personal air samples taken in the vicinity of repairmen blowing dust from brake drums with compressed air showed an average concentration of 16 fibres $/ \mathrm{ml}$ of air. Measurable concentrations were also found to exist at least $75 \mathrm{ft}(20-25 \mathrm{~m})$ from the worksite for about 15 minutes after compressed air blowing. The authors also noted that there was "minimal effort" तु control exposure to dust in the garages surveyed. Few workmen were observed to wear respirat ofy protection and few were aware of the potential heafth hazard associated with inhaling brake dust.

Similar fibre concentrations were found by Loringer et al in a study of brake repair workers in New Yojk City. "The mean fibre concentration for persolfal samples was 3.8 fibres $/ \mathrm{ml}$ whereas backgroưd concentrations ranged from 0.4 to $29.4 \mathrm{f} / \mathrm{ml}$ (mezin $15.9 \mathrm{f} / \mathrm{ml}){ }^{11}$

Previous studies indicate that under certain circumstances, free chrysotile asbestos may liberated from brake materials. ${ }^{12}{ }^{13}$ Exposure to fræe, unaltered fibres may occur during brake maintenance and it therefore appears that car servicing person may be exposed to both "altered" and "unalteregु"
chrysotile asbestos fibres.

Complicating the issue of the risk of mesotheliona associated with clutch and brake maintenance is thre current controversy over the potential of chrysotile cause this malignancy. Although epidemiologieal evidence suggests the existence of a gradient in potengy to induce this tumour among different fibre types (with crocidolite being the most potent and chrysotile the least), recent analyses of workers in the chrysintile mining, textile, and friction products industries shof pronounced differences in the incidence of diserase given comparable exposures. ${ }^{14}$ Differences in the dimensions may account for these discrepanci蔡; processed chrysotile fibres used in seconda industries may differ from mined chrysotile. Afso consumer use of certain products containigg chrysotile produce altered fibres of potentialy increased pathogenicity. ${ }^{14}$

Although the risk of mesothelioma posed exposure to chrysotile asbestos during brake aed clutch maintenance and repair is currently poofy defined, improved estimates of duration and intensîy of exposure, the physical characteristics of potentialy respirable fibres, and a clearer understanding of the aetiological role of chrysotile in the development $\widehat{\theta} f$ mesothelioma would serve to define more accuratefy the risk of this malignancy among this occupation group.

This work was partially completed while one of the authors (MH) was affiliated with the Canadian Tumor Reference Center. We thank the Canadian Tumor Reference Center for providing materials for tyis report.

Requests for reprints to: Michael Huncharek, MP Box 487, Boston University School of Medicine, 80 East Concord Street, Boston, Mass 02118. 


\section{References}

1 Huncharek M. The biomedical and epidemiological characteristics of asbestos related diseases: a review. Yale J Biol Med 1986;59:435-51.

2 Quinn MM, Kriebel D, Buiatti E, et al. An asbestos hazard in the reprocessed textile industry. Am J Ind Med 1987;11:255-66.

3 Young I, West S, Jackson J, Cantrell P. Prevalence of asbestos related lung disease among employees in non-asbestos industries. Med J Aust 1981;1:464-7.

4 Stove MJ. Clinical studies in asbestosis. American Review of Tuberculosis 1940;41:12-26.

5 Boillat MH, Lob M. Risk of asbestosis in workers employed in replacing automobile brake linings. Schweizerische Medizinische Wochenschrift 1973;103:1354-9.

6 Langer AM, McCaughey WTE. Mesothelioma in a brake repair worker. Lancet 1982;ii:1101-3.

7 Selikoff IJ, Lee DH. Asbestos and disease. New York: Academic Press, 1978.
8 Li FP, Lokich J, Lapey J, Neptune WB, Wilkins EW. Familial mesothelioma after intense asbestos exposure at home. JAMA 1978;240:467.

9 Castleman B, Camoraota LA, Fritsch AJ, Mazzocchi S, Cranley RG. The hazards of asbestos for brake mechanics. Pub Health Rep 1975;90:254-6.

10 Rohl AN, Langer AM, Wolff MS, Weisman I. Asbestos exposure during brake lining maintenance and repair. Environ Res 1976;12:110-28.

11 Lorimer WV, Rohl AN, Miller A, Nicholson WJ, Selikoff IJ. Asbestos exposure of brake repair workers in the United States. Mt Sinai J Med 1976;43:207-18.

12 Hickish DE, Knight LL. Exposure to asbestos during brake maintenance. Ann Occup Hyg 1970;13:17-21.

13 Lynch J. Brake lining decomposition products. J Air Pollut Control Assoc 1968;18:824-6.

14 Huncharek M. The epidemiology of pleural mesothelioma: current concepts and controversies. Cancer Invest (in press). 